\author{
Ricarda Rühl \\ Magdalena M. Wozniak \\ Michael Werk \\ François Laurent \\ Georg Mager \\ Michel Montaudon \\ Andreas Pattermann \\ Antoine Scherrer \\ Jean-Pierre Tasu \\ Maciej Pech \\ Jens Ricke
}

\section{CsI-detector-based dual-exposure dual energy in chest radiography for lung nodule detection: results of an international multicenter trial}

Published online: 2 September 2008

(C) European Society of Radiology 2008

The online version of the original article can be found at http://dx. doi.org/10.1007/s00330-008-0945-6.

\author{
R. Rühl $(\square)$ \\ Universitätsklinikum Magdeburg, Klinik für Radiologie und \\ Nuklearmedizin, Leipzigerstr. 44, \\ 39120 Magdeburg, Germany \\ e-mail: ricarda.ruehl@medizin. \\ uni-magdeburg.de \\ Tel.: +49-391-6713030 \\ Fax: +49-391-6713029
}

M. M. Wozniak

Dziecięcy Szpital Kliniczny Akademii Medycznej w Lublinie, Lublin, Poland

M. Werk

Universitätsmedizin Berlin,

Charité CVK,

Berlin, Germany

F. Laurent

Hôpital Haut-Lévèque, Le Centre, Hospitalier Universitaire de Bordeaux, Hôpitaux de Bordeaux,

Pessac, France

G. Mager

Bundeswehrkrankenhaus, Berlin,

Berlin, Germany

M. Montaudon

Hôpital Haut-Lévèque, Le Centre Hospitalier Universitaire de

Bordeaux, Hôpitaux de Bordeaux,

Pessac, France
A. Pattermann
Wilhelminenspital,
Vienna, Austria

\section{Erratum to: Eur Radiol(2008)18(9):1831-1839 DOI 10.1007/s00330-008-0945-6}

Unfortunately, the authors supplied a false value for the specificity of the dual-energy application tested in their trial. The specificity for the detection of lung nodules with dual energy is not $55.2 \%$, as given in the abstract, the section entitled "Lesion detection" (rounded to 55\% in both cases), and in Table 3, but $78.0 \%$.

However, the error does not change the conclusions drawn. Even with the corrected value the results remain insignificant with respect to differences between standard digital radiography alone and in conjunction with dualenergy radiography for nodule detection.

The authors very much regret their error.

\author{
A. Scherrer \\ Hôpital Foch, \\ Foch, France \\ J.-P. Tasu \\ Le Centre Hospitalier Universitaire \\ de Poitiers, \\ Poitiers, France \\ M. Pech · J. Ricke \\ Universitätsklinik Magdeburg, Klinik für Radiologie und \\ Nuklearmedizin, \\ Magdeburg, Germany
}

